\title{
A High-Efficiency and Low-Cost Converter For Photovoltaic Water Pumping System
}

\author{
Pranjali Shrivastava ${ }^{1}$, Rishabh Shukla ${ }^{2}$ \\ ${ }^{1} \mathrm{M}$. Tech Scholar, Oriental College of Technology (RGPV), Bhopal, India \\ ${ }^{2}$ Professor, Oriental College of Technology (RGPV), Bhopal, India
}

\begin{abstract}
A new design of an efficient battery less pumping system powered from photovoltaic panels, comprising a push-pull converter As Well as an induction motor, is presented. full valuation of the energy processing cycle has acceptable the formulation of a situate of propose principles and the optimization of a sensor less induction motor drive system. The resulting presentation improvement is established experimentally. These techniques vary in many aspects as: simplicity, convergence speed, digital or analogical execution, sensors necessary, cost, range of efficiency, and in other aspects. This paper is study about high efficiency and low cost of pv water pumping system.
\end{abstract}

Keywords: Maximum power point tracking, Pv array, Photovoltaic effect.

\section{Introduction}

Photovoltaic panels are recurrently used for agricultural action, For the most part in isolated areas or where the utilization of an alternating energy resource is selected. In exacting, they have been established time and time again to reliably manufacture sufficient electricity unswervingly from solar radiation (sunlight) to power livestock and irrigation watering systems. Photovoltaic skill is one of the most gifted for distributed low-power electrical production. The steady diminution of charge per peak watt over fresh years and the effortlessness with which the installed power can be improved by adding panels are some of its attractive features. Among the many applications of photovoltaic energy, pumping is one of the most talented. In photovoltaic pump-storage system, solar energy is pile up, when sunlight is reachable, as potential energy in a water reservoir and obsessive according to demand. There are advantages in avoiding the use of huge banks of lead acid batteries, which are weighty and expensive and have one- fifth of the natural life of a photovoltaic panel. It is significant, however, that the absence of batteries does not compromise the efficiency of the end-to-end power conversion chain, from panels to mechanical pump. A classic configuration of a battery less photovoltaic pumping system is shown in Fig. 1. The systems include the subsequent apparatus: 1. photovoltaic panels $2 . \mathrm{dc} / \mathrm{dc}$ converter 3. dc/ac inverter 4. induction motor and 5. centrifugal pump. The plan of an proficient photovoltaic pumping system without the use of a battery bank stands for a significant dare. It is essential to deal with the effect of the stochastic nature of solar isolation on the entire energy conversion chain, including the nonlinear features of photovoltaic panels, the voltage boost converter, and the electromechanical power alteration tool. In general terms, it is essential to attain the best performance from each system module over a wide input power range. Photovoltaic panels necessitate specific control techniques to ensure procedure at their maximum power point (MPP). Impedance matching issues mean that photovoltaic arrays may activate more or less professionally, depending on their series/parallel pattern. In this paper, a minimum number of series connections are accepted. This implies that a comparatively high dc voltage gain (between six and ten) is essential to provide the drive voltage necessary by the induction motor. The projected system uses a push-pull converter and is based on the solution offered in [3]. The choice for this precise $\mathrm{dc} / \mathrm{dc}$ converter topology is essentially dictated by the necessity for galvanic isolation between the low- and highvoltage sides. Such a necessity precludes the use of low-cost and high-effectiveness converter topologies [4]. A study of how the converter topology influence the MPP tracking (MPPT) of a photovoltaic system is detailed in [1] and [4].

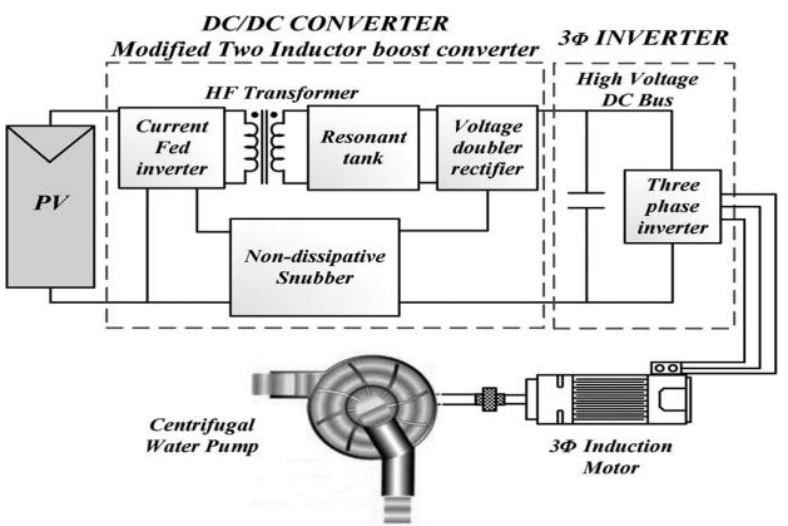

Figure 1: Components of a photovoltaic pumping system not requiring a lead-acid battery bank

\section{Solar Radiation, Solar Irradiance, and $\mathbf{P v}$ Insolation}

To aim a solar-powered water pump system, you will require quantifying the accessible solar energy. It is consequently significant for you to be known with the definitions and distinctions between the three associated terms -solar radiation," -solar irradiance," and -solar isolation."

Solar radiation is the energy from the sun that reaches the earth. It is commonly uttered in units of kilowatts per square meter $\left(\mathrm{kW} / \mathrm{m}^{2}\right)$. The earth receives a nearly constant 1.36 $\mathrm{kW} / \mathrm{m}$ of solar radiation at its external environment. However, by the time this energy reaches the earth's surface, the total 


\section{International Journal of Science and Research (IJSR) \\ ISSN (Online): 2319-7064}

Index Copernicus Value (2013): 6.14 | Impact Factor (2014): 5.611

amount of solar radiation is compact to just about $1 \mathrm{~kW} / \mathrm{m} 2$.

The greatness of sunshine (i.e. solar radiation) vary according to on geographic location. A good quality analogy to describe this variation is the dissimilar circumstances that can be originate on the north slope of a mass versus its south slope. The strength of sunlight in addition vary based on the time of day because the sun's energy must pass through different amounts of the earth's atmosphere as the incident angle of the sun changes. Solar strength is utmost when the sun is straight overhead and light is transient through the least quantity of atmosphere. on the other hand, solar intensity is slightest during the early morning and late afternoon hours when the sunlight pass through the maximum amount of atmosphere. In the majority areas, the most prolific hours of sunlight are from 9:00 a.m. to 3:00 p.m. Outside of this time range, solar power might still be formed, but at much lower levels.

Solar irradiance, on the other hand, is the quantity of solar energy established by or projected onto a precise surface. Solar irradiance is moreover accessible in units of $\mathrm{kW} / \mathrm{m} 2$ and is calculated at the exterior of the objects. In the case of a PV- powered system, this surface is the solar panel. in conclusion, solar isolation is the amount of solar irradiance deliberate over a given phase of time. It is naturally quantified in peak sun hours, which are the equivalent number of hours per day when solar irradiance averages $1 \mathrm{~kW} / \mathrm{m} 2$. It is significant to note that even though the sun may be beyond the horizon for 14 hours in a given day, it can only produce energy corresponding to 6 peak sun hours.

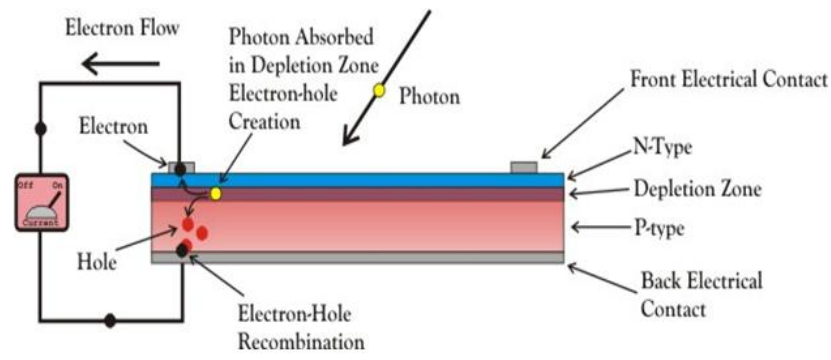

Figure 2: PV Working

\section{MPPT Control}

As identified the output power uniqueness of the PV system as function of irradiance and temperature curves are nonlinear and are critically inclined by solar irradiation and temperature. Furthermore, the daily solar irradiation diagram has sudden variations during the day, as shown in Fig. 2. below these situation, the MPP of the PV array change constantly; consequently the PV system's working point must transform to take full advantage of the energy created. An MPPT technique is therefore used to keep the PV array's in service point at its MPP. There are many MPPT process accessible in the literature; the bulk of widely-used methods are illustrate in the following sections, starting with the simplest method.

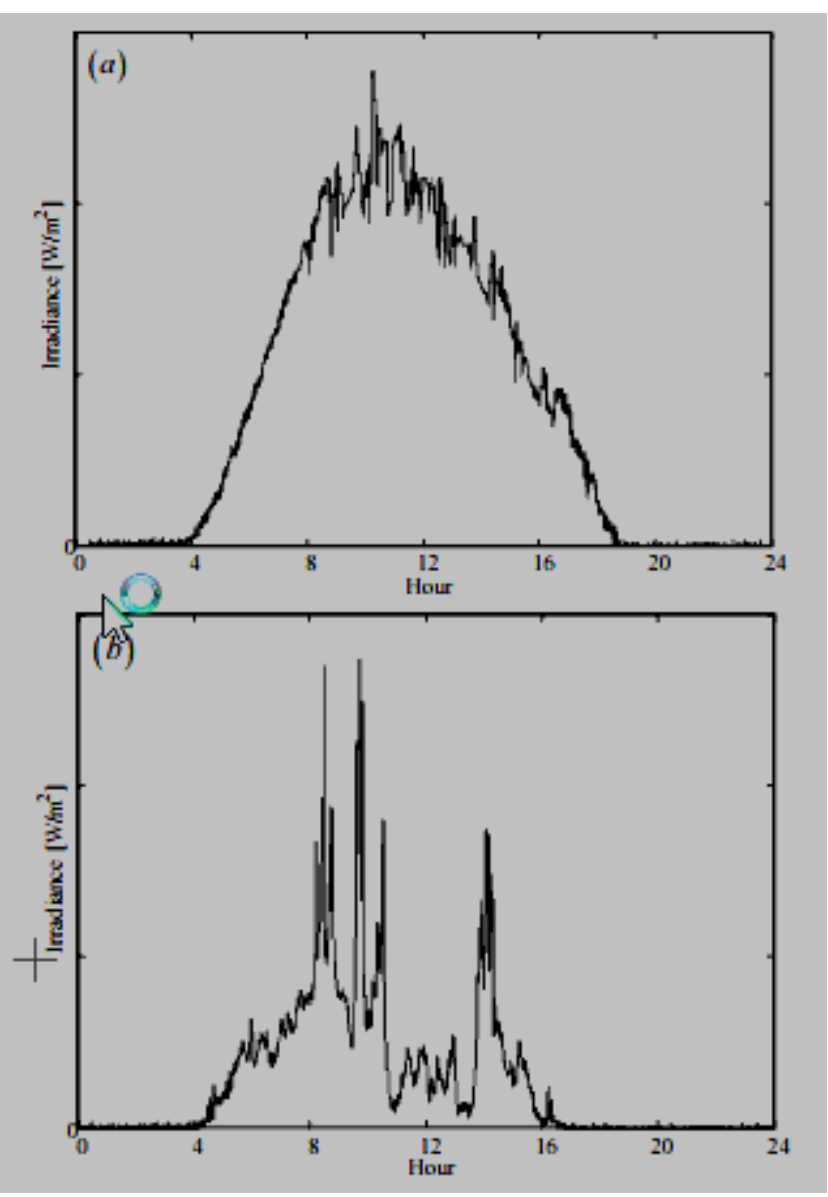

Figure 3: Daily solar irradiation diagram: (a) sunny day (b) cloudy day

The MPPT is a policy worn to make certain that the operating position of the system is kept at the MPP of the PV panel .The extensively used hill-climbing algorithm was useful due to its easy execution and fast dynamic response. This MPPT process is based on the type of the power curve of the PV panel. This curve can be further divided into two sides, to the left and right of the MPP. After analyze the power and voltage deviation, one can deduce in which side of the curve the PV panel is at present in use and regulate the voltage situation to get closer to the desired point. The voltage orientation is worn on a PI controller to boost or decrease the motor speed and consequently adjust the bus and panel voltage by changing its operating point.

\section{Hysteresis Control Method}

The core negative aspect of the typical TIBC is its incapacity to function with no load or even in low-load situations. The TIBC input inductors are charged even if there is no output current, and the power of the inductor is newly transfer to the output capacitor raise its voltage for an indefinite period until its breakdown. usually, the input MOSFET cannot be turned off because there is no reserve pathway for the inductor current. However, with the adding up of the projected snubber, the TIBC switches can be turned off. Consequently, a hysteresis controller can be correlate based on the dc bus voltage intensity. Each time a highest voltage limit is achieved, representing a low-load incident, this approach of operation begin. In this case, the switches are turned off 


\section{International Journal of Science and Research (IJSR) \\ ISSN (Online): 2319-7064}

Index Copernicus Value (2013): 6.14 | Impact Factor (2014): 5.611

awaiting the dc bus voltage returns to a normal predefined stage.

\section{Constant Voltage Method}

The Constant Voltage algorithm is the easiest MPPT control technique. The operating point of the PV array is reserved near the MPP by changeable the array voltage and matching it to a set reference voltage Vref. The Vref value is set equal to the VMPP of the feature PV module This technique assume that particularly insulation and temperature deviations on the array are not so important, and that the constant reference voltage is an adequate estimate of the accurate MPP. Operation is therefore never exactly at the MPP and dissimilar data has to be composed for different geographical sections. The CV technique does not need any input. However, aspect of the voltage VPV is compulsory in categorize to set up the duty-cycle of the dc/dc SEPIC by PI regulator, as shown in the block diagram of Fig. 3. It is significant to monitor that when the PV panel is in low insulation circumstances, the $\mathrm{CV}$ method is more effective than either the P\&O method or the IC method.

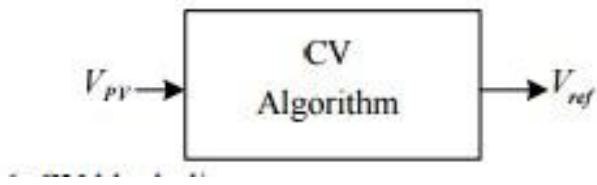

Figure 4: CV block diagram

\section{Existing Method}

The bulk of profitable systems use low-voltage dc motors, thus avoid a boost stage involving the PV module and the motor. Unhappily, dc motors have lower efficiency and higher preservation cost evaluated to induction motors and are not appropriate for functions in isolated areas, where there is no focused persons for in use and maintain these motors. Another problem is that low-voltage dc motors are not common items in the local marketplace. Because of the abovementioned troubles.

\section{Proposed Method}

In proposed technique the converter is planned to drive a three-phase induction motor straight from PV energy. Due to its better robustness, minor price, higher effectiveness, accessibility in local markets, and lower preservation cost compared to other types of motors. The water pumping system is a stand-alone system without support. The system consists of a single PV module, a maximum power point tracker, and a DC water pump. Proposed System Maximum power point tracker is now common in grid-tied PV power systems and is becoming more popular in stand-alone systems. Analog controllers have traditionally performed control of MPPT. Nevertheless, the use of digital controllers is speedily increasing because of their reward over analog controllers. First, digital controllers are able of implementing advanced algorithm with comparative easiness It is far easier to code the equation, $\mathrm{x}=\mathrm{y} \times \mathrm{z}$, than to design an analog circuit to do the same. Digital controllers are resistant to time and temperature flow because they work in discrete, outside the linear procedure. As a effect, they suggest long-term firmness. They are also insensitive to component tolerances.

\section{Simulation Model}

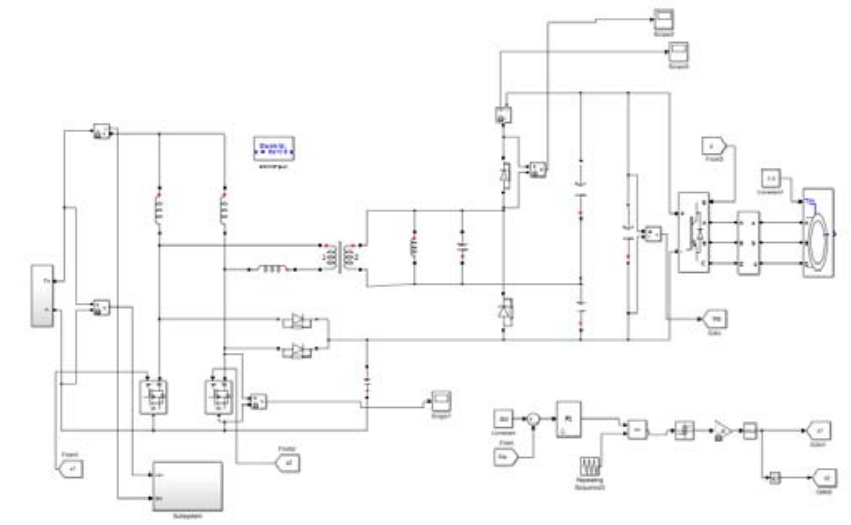

Figure 5: Simulation Model

\section{Simulation Result}

These are the different waveforms of current and voltages which are improved and better than previous model.

\section{1) Pv voltage}

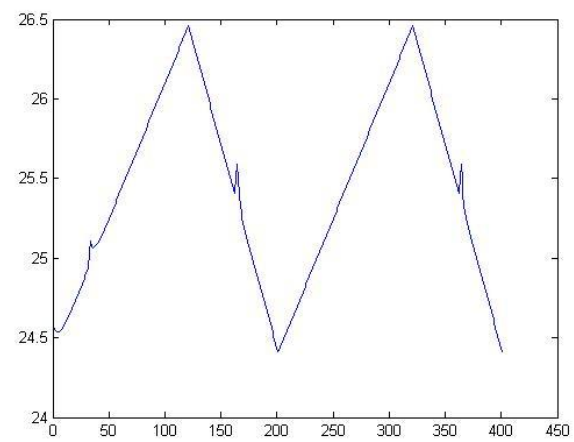

Figure 6: pv voltage

\section{2) Pv Current}

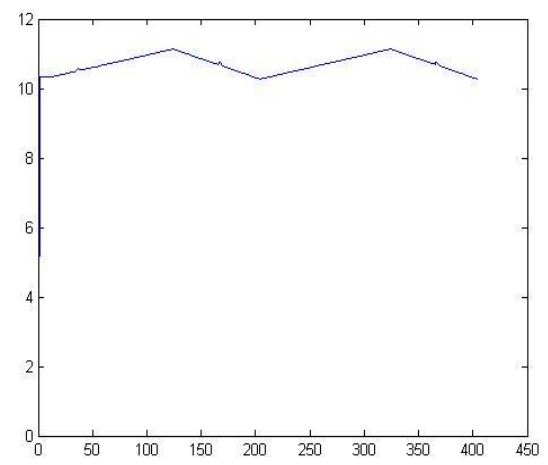

Figure 7: Pv current

\section{3) Mosfet Voltage}




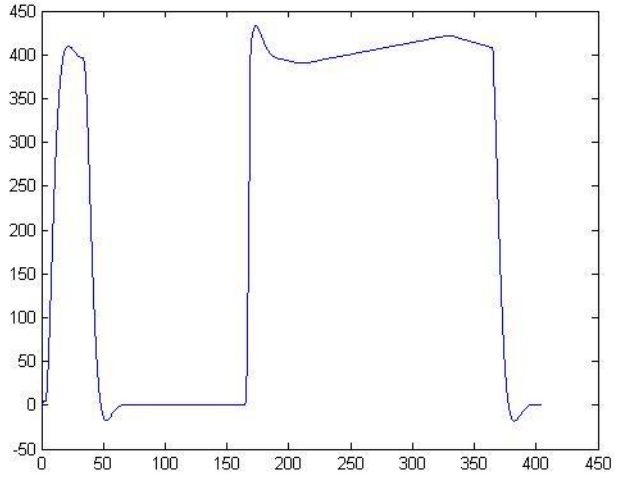

Figure 8: mosfet voltage

\section{4) Diode Voltage}

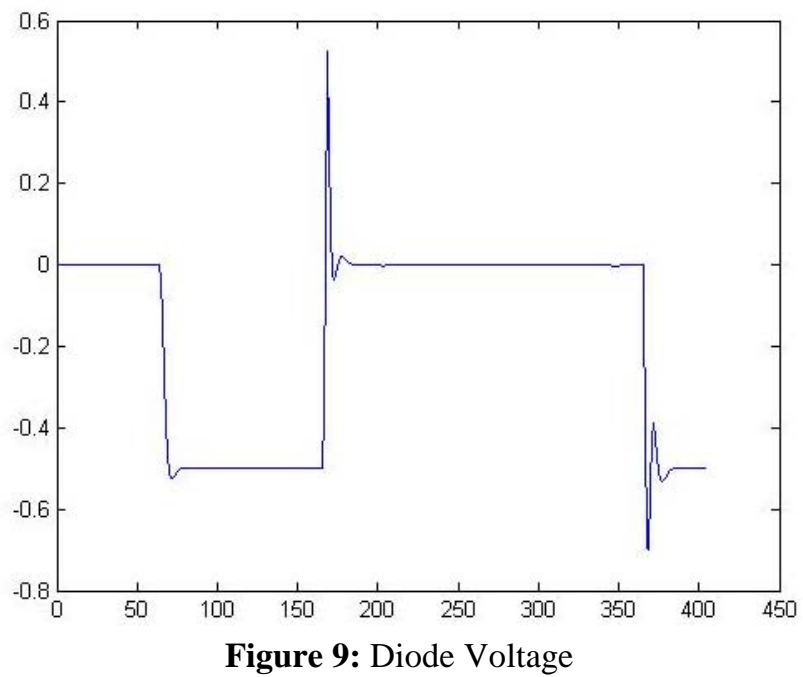

\section{Conclusion}

In this mission, a converter for PV water pumping and treatment systems devoid of the use of storage elements was existing. The converter was planned to drive a three-phase induction motor straightforwardly from PV solar energy and was considered to be a commercially feasible clarification having low cost, high efficiency, and robustness. This project presented the arrangement block diagram, control algorithm, and design. The simulation results imply that the proposed resolution could be a viable option after more consistency tests are execute to guarantee its robustness.

\section{References}

[1] M. Chunting, M. B. R. Correa, and J. O. P. Pinto, - The IEEE 2011 international future energy challengeRequest for proposals," in Proc. IFEC, 2010, pp. 1-24.

[2] A. Hahn, Fechnical maturity and reliability of photovoltaic pumping systems," in Proc. 13th Eur. Photovoltaic Solar Energy Conf., Nice, France, pp. 1783-1786.

[3] M. A. Vitorino and M. B. R. Correa, High performance photovoltaic pumping system using induction motor," in Proc. Brazilian Power Electron. Conf., 2009, pp. 797804.
[4] G. Teröde, K. Hameyer, and R. Belmans, Sensorless control of a permanent magnet synchronous motor for PV-powered water pump systems using the extended Kalman filter," in Proc. 9th Int. Conf. Elect. Mach. Drives, 1999, pp. 366-370.

[5] H. Harsono, Photovoltaic water pump system," Ph.D. dissertation, Dept. Intell. Mech. Syst. Eng., Faculty Kochi Univ. Technol., Kochi, Japan, Aug. 2003.

[6] D. Linden, Handbook of Batteries and Fuel Cells. New York, NY, USA: McGraw-Hill, 1984.

[7] D. Tschanz, H. Lovatt, A. Vezzini, and V. Perrenoud, -A multi-functional converter for a reduced cost, solar powered, water pump," in Proc. IEEE ISIE, 2010, pp. 568-572.

[8] M. A. Vitorino, M. B. R. Correa, C. B. Jacobina, and A. M. N. Lima, -Aneffective induction motor control for photovoltaic pumping," IEEE Trans. Ind. Electron., vol. 58, no. 4, pp. 1162-1170, Apr. 2011.

[9] S. R. Bowes and A. Midoun, Suboptimal switching strategies for microprocessor controlled PWM inverter drives," Proc. Inst. Elect. Eng.-Elect. Power Appl., vol. 132, no. 3, pp. 133-148, May 1985.

[10] M. Cacciato, A. Consoli, and V. Crisafulli, -Ahigh voltage gain dc/dc converter for energy harvesting in single module photovoltaic applications," in Proc. IEEE ISIE, 2010, pp. 550-555.

[11]P. J. Wolfs, - Acurrent-sourced dc-dc converter derived via the duality principle from the half-bridge converter," IEEE Trans. Ind. Electron., vol. 40, no. 1, pp. 139-144, Feb. 1993.

[12] P. Wolfs and Q. Li, -Ananalysis of a resonant half bridge dual converter operating in continuous and discontinuous modes," in Proc. IEEE Power Electron. Spec. Conf., 2002, pp. 1313-1318.

\section{Author Profile}

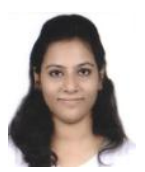

Pranjali Shrivastava received the B.E. degree in electrical and electronics engineering from Gyan Ganga college of technology Jabalpur(m.p.) in 2013 and M.TECH. degree in power electronics from Oriental College of Technology, Bhopal (RGPV Bhopal) in 2015 year.

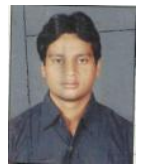

Rishabh Shukla received his B.E. degree in electcrical and electronics engineering from Lakshmi narain college of technology Bhopal (M.P.) in 2010 and Master of Enginnering In power electronics from Samrat Ashok Technological Institute Vidisha (M.P.) in 2013. From 2013 to present he is working as an Assistant professor in electrical and electronics department in oriental college of technology, Bhopal(M.P.) and his area of interest is in Simulation Of Cycloconverter\& Its Application In Adjustable Speed Drive. 